\title{
Vitamin B12 and folate concentrations in serum and cerebrospinal fluid of neurological patients with special reference to multiple sclerosis and dementia
}

\author{
T Q Nijst, R A Wevers, H C Schoonderwaldt, O R Hommes, A F J de Haan
}

\begin{abstract}
Vitamin B12 and folate concentrations were measured in serum and cerebrospinal fluid (CSF) in 293 neurological patients. Serum and CSF vitamin B12 concentrations showed a positive correlation. In individual patients CSF B12 concentrations varied considerably for a given serum concentration. The median serum vitamin B12 concentration of the Alzheimer's type dementia group was significantly lower compared with that of a control group. Lower median CSF vitamin B12 concentrations were found in groups of patients with multiple sclerosis and Alzheimer's type dementia. Five patients with heterogeneous clinical pictures had unexplained low serum and CSF B12 concentrations without macrocytosis. Two patients had very high serum $B 12$ and low-normal CSF concentrations which could be explained by a blood-brain barrier transport defect. Serum and CSF folate concentrations did not show significant differences between the various groups.
\end{abstract}

Vitamin B12 deficiency may cause neurological complications. ${ }^{1}$ These complications can appear independently of possible haematological changes. ${ }^{2}$ During the 1950 s and $60 \mathrm{~s}$, several studies ${ }^{3-6}$ were carried out on vitamin B12 concentrations in multiple sclerosis because of the suspected role of this vitamin in myelin formation. Using the now obsolete microbiological assay techniques, the results were conflicting and interest waned.

Recently Reynolds ${ }^{78}$ discussed a possible relation between low serum B12 concentrations and multiple sclerosis. The connection between low serum vitamin B12 concentrations and dementia has been investigated more recently. Cole ${ }^{9}$ and $\mathrm{Karnaze}^{10}$ independently found significantly lower serum B12 concentrations in Alzheimer's type dementia. CSF vitamin B12 levels were not determined in their studies. It is important to recognise this relation because there are indications that some of the patients may improve after receiving high doses of parenteral vitamin B12. ${ }^{11}$

To examine the relation between vitamin B12 and neurological disorders, cerebrospinal fluid (CSF) vitamin B12 could provide important additional information. The vitamin B12 status of the brain may be better represented by the CSF vitamin B12 concentration. This study analysed retrospectively the vitamin $\mathrm{B} 12$ and folate concentrations in serum and CSF in 293 neurological patients.

\section{Patients}

Since January 1985 the investigation of neurological disorders of unknown origin in our department has included the determination of vitamin $\mathrm{B} 12$ and folate concentrations in serum and CSF. In October 1987, 337 patients (age $>10$ years) have had retrospectively such investigation and they form the basic frame of this study. We excluded from the study patients receiving vitamin $\mathrm{B} 12$ or folate medication and patients with elevated amounts of erythrocytes, free haemoglobin ( $>0.10 \mu \mathrm{mol} / \mathrm{l}$ ) or bilirubin $(>0.15 \mu \mathrm{mol} / \mathrm{l}$ ) in the CSF. Others not included were patients who had partial gastrectomy or a history of pernicious anaemia. Thus 293 patients remained (129 males and 164 females, age range: 11-83 years). Almost all patients were non-institutionalised and receiving symptomatic drug treatment. The patients were divided into the following groups:

1) Multiple sclerosis: 58 definite MS patients. 2) Myelopathy: 15 patients (posterior column and/or pyramidal tract lesions of unknown cause. (7), cervical spondylosis (3), arteriosclerosis of the spinal cord (2), radiation myelopathy (1), Friedreich's disease (1), Paget's disease (1)). 3) Alzheimer's-type dementia: 10 patients. 4) Non Alzheimer'stype dementia: 15 patients (organic brain syndrome (4), multi-infarct dementia (5), normal pressure hydrocephalus (5), Creutzfeldt Jakob disease (1)). 5) Reference group: 157 patients with a neurological disease from which no association with low vitamin B12 or low folate concentrations is known.

A heterogeneous group of 38 patients remained and was not included in the calculations. These patients had neurological disorders that can be caused by low vitamin B12 or folate concentrations (subacute combined system degeneration, metabolic encephalopathy, polyneuropathy, epilepsy and depression).

\section{Methods}

Fasting CSF samples for diagnostic purposes were obtained by lumbar puncture between 
8am and 9am. Vitamin B12 was measured with the Quantaphase B12/folate radio assay (Biorad 1911002, California, USA), using immobilised affinity-purified porcine intrinsic factor and folate binding proteins. The method was carried out according to the instructions of the manufacturer with the following exceptions: CSF samples $(4 \mathrm{ml})$ were evaporated until dryness in a Vortex evaporator/Buchler Instruments Inc, New York, United States and subsequently taken up in $0.5 \mathrm{ml}$ of the Bio-rad zero standard. In the assay only $50 \mu \mathrm{l}$ instead of $100 \mu \mathrm{l}$ of the microbead reagent were used, both for blood and CSF determinations. After a one hour incubation period and subsequent centrifugation, we added a washstep with $1 \mathrm{ml}$ saline. Samples were always determined in duplicate. Two additional standards ( 18 and 37 $\mathrm{pmol} / \mathrm{l}$ ) were used for the low vitamin B12 concentration range. For the determination of CSF folate the sample was diluted with the Bio-rad zero standard $(50 \% \mathrm{v} / \mathrm{v})$.

\section{Statistics}

Using an appropriate linear model, contrast tests were applied for testing equality of slopes of the regression equations. For comparing the levels of the parameters between the first five groups, a Kruskal-Wallis test was performed with confidence level alpha $=0.05$, followed (in case of a significant result) by two tailed Wilcoxon tests with confidence level alpha $=0.025$, correcting for multiple comparisons.

\section{Results}

\section{Age and sex dependency}

In the reference group, neither vitamin B12 and folates serum and CSF concentrations nor CSF:serum ratios changed significantly with increasing age. B12 and folate concentrations and CSF:serum ratios were not sex-related.

Correlation between serum and CSF concentrations

As shown in table 1 , there is a positive correlation between serum and CSF vitamin B12 concentrations in the various groups. In individual patients, however, CSF B12 concentrations vary considerably for a given serum B12 concentration. The regression equations of the various groups do not differ significantly compared with the regression equation of the reference group. The intercepts do not deviate significantly from zero.

Serum and CSF folate concentrations showed a positive correlation (all patients with serum folate $<35 \mathrm{nmol} / \mathrm{l}: \mathrm{r}=0.53, \mathrm{p}<0.01$; regression equation: $\mathrm{Y}=0.93 \mathrm{X}+14.97$ with $\mathrm{Y}=\mathrm{CSF}$ folate and $\mathrm{X}=$ serum folate concentration).

\section{Differences between the diagnostic groups}

Table 2 shows the median and the $5 \%$ range of the vitamin B12 and folate concentrations in CSF and serum of the various groups and the CSF:serum ratio of both vitamins. The median serum B12 concentration in the Alzheimer's type dementia group was lower than in the reference group $(p=0.016)$. Both the multiple sclerosis group $(P=0.014)$ and the Alzheimer's-type dementia group $(P=0.024)$ had lower median CSF B12 concentrations compared with that of the reference group.

Serum and CSF folate concentrations did not show significant differences between the various groups.

\section{Individual patients}

Table 3 shows some individual patients with their neurological diagnoses, who deserve further attention. The 13 patients with a low CSF:serum ratio for vitamin $\mathrm{B} 12$ (below $0.01=5^{\circ}{ }_{0}$ value of the reference group) had various neurological disorders (table 3A). In 11 cases the low ratio could be explained by a low CSF B12 concentration and in two cases by an extremely high serum B12 concentration. In all, six patients had a serum vitamin $\mathrm{B} 12$ concentration above $700 \mathrm{pmol} / \mathrm{l}$ (table 3B) although none of them was known to have a disorder which could be responsible for such a high vitamin B12 concentration.

Twenty seven patients had a serum and/or CSF vitamin B12 concentration below the 5\% value of the reference group. None of them had macrocytic anaemia (MCV range: 81-96 fl. and Hb range: $7 \cdot 8-9.8 \mathrm{mmol} / \mathrm{l})$. Only five patients had both a serum concentration below $142 \mathrm{pmol} / 1$ and a CSF concentration below $2 \cdot 1 \mathrm{pmol} / 1$. Their neurological disorders are shown in table $3 \mathrm{C}$.

\section{Discussion}

Lazar $^{12}$ concluded that there is no correlation between serum and CSF vitamin B12 levels. This study, however, showed a clear relationship between both concentrations $(r=0.61$

Table 1 The correlation between serum and CSF vitamin B12 concentrations. (Patients with serum vitamin B12 below 700 pmol $/ l . N=249$ )

\begin{tabular}{|c|c|c|c|c|}
\hline & Number & $\begin{array}{l}\text { Correlation } \\
\text { coefficient (Pearson) }\end{array}$ & Regression equation ${ }^{\star}$ & $\begin{array}{l}\text { Significance of the } \\
\text { corr/coefficient }(P)\end{array}$ \\
\hline $\begin{array}{l}\text { REF } \\
\text { MS } \\
\text { ALZ DEM } \\
\text { NON A DEM } \\
\text { MYEL }\end{array}$ & $\begin{array}{r}153 \\
57 \\
10 \\
15 \\
14\end{array}$ & $\begin{array}{l}0.58 \\
0.66 \\
0.41 \\
0.78 \\
0.59\end{array}$ & $\begin{array}{l}\mathrm{Y}=0.032 \mathrm{X}+0.40 \\
\mathrm{Y}=0.024 \mathrm{X}+0.95 \\
\mathrm{Y}=0.019 \mathrm{X}+1.68 \\
\mathrm{Y}=0.026 \mathrm{X}+0.90 \\
\mathrm{Y}=0.019 \mathrm{X}+4.38\end{array}$ & $\begin{aligned}<0.01 \\
<0.01 \\
0.24 \\
<0.01 \\
<0.05\end{aligned}$ \\
\hline ALL & 249 & 0.61 & $Y=0.029 X+0.90$ & $<0.01$ \\
\hline
\end{tabular}

$\star Y=$ CSF B12, $\mathrm{X}=$ SERUM B12.

$\mathrm{REF}=$ Reference group, $M S=$ Multiple sclerosis group, ALZ DEM = Alzheimer's type dementia group, NON A

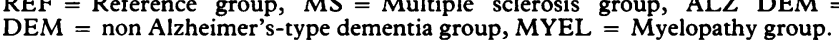


Table 2 Vitamin $B 12$ (pmol/l) and folate ( nmol/l) concentrations in serum and CSF (median and $5^{\circ}{ }_{0}-95^{\circ}$ o range)

\begin{tabular}{|c|c|c|c|}
\hline & \multicolumn{3}{|c|}{ Vitamin B12 } \\
\hline & $C S F$ & SERUM & CSF/SERUM $(\times 100)$ \\
\hline \multirow[t]{2}{*}{ REFERENCE } & $8 \cdot 7$ & 284 & $3 \cdot 0$ \\
\hline & $2 \cdot 1-22 \cdot 9$ & $142-541$ & $1 \cdot 0-6 \cdot 6$ \\
\hline \multirow{3}{*}{$\begin{array}{l}\text { MS } \\
\text { MYELOPATHY }\end{array}$} & $6 \cdot 9^{\star}$ & 255 & 2.8 \\
\hline & $\begin{array}{l}0.9-22 \cdot 3 \\
11 \cdot 4\end{array}$ & $\begin{array}{l}124-618 \\
349\end{array}$ & $\begin{array}{l}0 \cdot 3-6 \cdot 4 \\
3 \cdot 8\end{array}$ \\
\hline & $4 \cdot 3-41 \cdot 9$ & $177-835$ & $1 \cdot 1-5 \cdot 0$ \\
\hline ALZH DEM & $6 \cdot 3^{\star}$ & $229 \star$ & $2 \cdot 6$ \\
\hline \multirow{4}{*}{ NON A DEM } & $\begin{array}{l}0 \cdot 0-9 \cdot 2 \\
7 \cdot 6\end{array}$ & $\begin{array}{l}125-320 \\
286\end{array}$ & $\begin{array}{l}0 \cdot 0-4 \cdot 9 \\
2 \cdot 7\end{array}$ \\
\hline & $1 \cdot 5-19 \cdot 4$ & $109-614$ & $1 \cdot 1-7 \cdot 5$ \\
\hline & \multicolumn{3}{|l|}{ FOLATE } \\
\hline & $C S F$ & $S E R U M$ & $C S F / S E R U M$ \\
\hline REFERENCE & $\begin{array}{l}24 \cdot 8 \\
14 \cdot 4-42 \cdot 1\end{array}$ & $\begin{array}{l}10 \cdot 4 \\
5 \cdot 5-19 \cdot 1\end{array}$ & $\begin{array}{l}2 \cdot 4 \\
1 \cdot 3-4 \cdot 3\end{array}$ \\
\hline \multirow[t]{2}{*}{ MS } & $27 \cdot 0$ & $10 \cdot 7$ & $2 \cdot 3$ \\
\hline & $14 \cdot 4-38 \cdot 0$ & $6 \cdot 1-22 \cdot 4$ & $1.4-3.6$ \\
\hline MYELOPATHY & $22 \cdot 2$ & $8 \cdot 4$ & $2 \cdot 4$ \\
\hline \multirow{2}{*}{ ALZH DEM } & $13 \cdot 2-39 \cdot 4$ & $\begin{array}{r}5 \cdot 7-24 \cdot 0 \\
10 \cdot 1\end{array}$ & $\begin{array}{l}1 \cdot 2-3 \cdot 8 \\
2 \cdot 4\end{array}$ \\
\hline & $14 \cdot 0-36 \cdot 2$ & $\begin{array}{r}10 \cdot 1 \\
4 \cdot 7-19 \cdot 4\end{array}$ & $\begin{array}{l}2 \cdot 4 \\
1 \cdot 7-3 \cdot 4\end{array}$ \\
\hline \multirow[t]{2}{*}{ NON A DEM } & $21 \cdot 2$ & $9 \cdot 5$ & $2 \cdot 4$ \\
\hline & $10 \cdot 4-33 \cdot 4$ & $3 \cdot 6-19 \cdot 7$ & $1 \cdot 0-3 \cdot 6$ \\
\hline
\end{tabular}

$\star P=<0.025$ versus reference.

$M S=$ Multiple Sclerosis, ALZH DEM = Alzheimer's type dementia, NON A DEM = non MS = Multiple Sclerosis,
Alzheimer's type dementia.
Our study can partly confirm the results of Cole and Karnaze. In the group of patients with Alzheimer's type dementia we found a $30 \%$ prevalence of serum B12 concentrations below $155 \mathrm{pmol} / 1$ (which is the $10 \%$ value of the reference group) against $13 \%$ in the group with "Non Alzheimer's type dementia". This difference, however, was not significant. Median serum and CSF vitamin B12 concentrations in the Alzheimer's type dementia group were significantly lower compared with those of the reference group and tended to be lower than those of the non Alzheimer's type dementia group. These findings stress the importance of the vitamin B12 status of the brain in Alzheimer's type dementia and may justify vitamin B12 supplementation in these patients.

Renvoize $^{14}$ reported a $44 \cdot 8 \%$ prevalence of folate deficiency in 150 patients with a diagnosis of dementia. Reynolds ${ }^{15}$ found a significant increase of organic brain syndrome and pyramidal tract damage in a group of patients with folate deficiency. In our study the serum and CSF folate concentrations were not significantly different between the groups.

Bauer $^{4}$ and O'Connor ${ }^{5}$ found reduced serum vitamin B12 concentrations in patients with multiple sclerosis using microbiological assay techniques (MBA). Basil ${ }^{3}$ and Schrumpf ${ }^{6}$ described slightly lower CSF B12 concentrations (MBA) in patients with multiple sclerosis. Our study, using a RIA technique to determine vitamin B12 concentrations, showed a lower median CSF B 12 concentration in the group of patients with multiple sclerosis $(P=0.014)$. The overlap in CSF vitamin B12 levels between the multiple sclerosis group and the reference group is such that CSF vitamin B12 cannot be used as a diagnostic parameter in multiple sclerosis.

The median CSF:serum ratio and the regression equations of the various groups did not differ significantly. This reflects an undisturbed blood-brain barrier function. Two

Table 3 Neurological diagnosis

\begin{tabular}{|c|c|c|c|c|c|c|}
\hline & $\operatorname{Sex}$ & Age (years) & Neurological diagnosis & $C S F$ & Serum & Ratio $(\times 100)$ \\
\hline \multicolumn{7}{|c|}{ ind serum vitamin $B 12$ in $p$} \\
\hline 1 & M & 32 & Multiple sclerosis & $<0.5$ & 297 & $<0 \cdot 17$ \\
\hline 2 & $\mathrm{~F}$ & 42 & Parkinson's disease & $<0.5$ & 190 & $<0.26$ \\
\hline 3 & $\mathrm{~F}$ & 64 & Alzheimer's type dem. & $<0.5$ & 125 & $<0.40$ \\
\hline 4 & $\mathrm{M}$ & 74 & Undiagnosed pain & $5 \cdot 9$ & $>1475$ & $<0.40$ \\
\hline 5 & $\mathrm{~F}$ & 34 & Multiple sclerosis & 0.9 & 211 & 0.43 \\
\hline 6 & $\mathrm{~F}$ & 42 & Multiple sclerosis & $0 \cdot 7$ & 153 & 0.46 \\
\hline 7 & $M$ & 54 & Shy Drager syndrome & $7 \cdot 6$ & 1440 & 0.53 \\
\hline 8 & $\mathrm{~F}$ & 67 & Vertebrobasilar ischaemia & $1 \cdot 0$ & 171 & 0.58 \\
\hline 9 & $M$ & 85 & Brain contusion & $2 \cdot 5$ & 351 & $0 \cdot 71$ \\
\hline 10 & $\mathrm{~F}$ & 18 & Cerebellar ataxia & $2 \cdot 1$ & 264 & $0 \cdot 80$ \\
\hline 11 & $\mathrm{M}$ & 44 & Locomotor ataxia & $1 \cdot 7$ & 178 & 0.96 \\
\hline 12 & $\mathrm{~F}$ & 31 & Multiple sclerosis & $1 \cdot 8$ & 183 & 0.98 \\
\hline 13 & F & 24 & Multiple sclerosis & $2 \cdot 4$ & 242 & 0.99 \\
\hline \multicolumn{7}{|c|}{ Patients with serum vitamin B12 level above $700 \mathrm{pmol} / 1$} \\
\hline 1 & F & 38 & Pyramidial tract lesion of unknown cause & 41.9 & 835 & $5 \cdot 02$ \\
\hline 2 & $\mathrm{~F}$ & 53 & Multiple sclerosis & $29 \cdot 7$ & 925 & $3 \cdot 21$ \\
\hline 3 & $\mathrm{~F}$ & 78 & Gait disturbances & $31 \cdot 1$ & 1129 & $2 \cdot 75$ \\
\hline 4 & $\mathrm{M}$ & 54 & Shy Drager syndrome & $7 \cdot 6$ & 1440 & 0.53 \\
\hline 5 & M & 74 & Undiagnosed pain & 5.9 & $>1475$ & $<0.40$ \\
\hline 6 & M & 49 & Parkinson's disease & $59 \cdot 8$ & $>1475$ & $<4.05$ \\
\hline \multicolumn{7}{|c|}{ Patients with low serum and CSF vitamin B12 levels (Serum $<142 \mathrm{pmol} / 1$ and CSF $<2 \cdot 1 \mathrm{pmol} / \mathrm{l}$ ) } \\
\hline 1 & F & 64 & Alzheimer's type dem. & $<0.5$ & 125 & $<0.40$ \\
\hline 2 & $\mathbf{M}$ & 59 & Creutzfeldt-Jakob disease & $1 \cdot 5$ & 132 & $1 \cdot 14$ \\
\hline 3 & $\mathbf{F}$ & 77 & Vertebrobasilar ischaemia & $1 \cdot 8$ & 101 & 1.78 \\
\hline 4 & $\mathbf{F}$ & 36 & Bulbar dysarthria & $1 \cdot 8$ & 102 & $1 \cdot 76$ \\
\hline 5 & M & 66 & Spinal cord compression & $2 \cdot 0$ & 75 & $2 \cdot 67$ \\
\hline
\end{tabular}


patients, however, had an extreme discrepancy between serum and CSF vitamin B12 values (table 3B: case 4 and 5) which could be explained by a blood-brain barrier transport defect.

We thank M J T Jansen and A van Rens for their technical assistance.

Chanarin I. The megaloblastic anaemias. Oxford: Blackwell, 1979:324-27.

2 Strachan RW, Henderson JG. Psychiatric syndromes due to avitaminosis B12 with normal blood and marrow. Quart $J$ Med 1965;135:303-18.

3 Basil W, Brown JK, Matthews DM. Observations on vitamin B12 in serum and cerebrospinal fluid in multiple sclerosis. J Clin Path 1965;18:317-21.

4 Bauer $\mathrm{H}$, Heinrich HC. Vitamin B12 metabolism in neurological disease. In: Folch-Pi J, ed. Chemical pathology of the nervous system. Oxford: Pergamon Press, 1961:120-25.

5 O'Connor JS, Davis RL, Langworthy OR. B12 metabolism and multiple sclerosis. Proc Soc Exp Biol Med 1960;103:180-83.
6 Schrumpf E, Bjelke E. Vitamin B12 in the serum and the cerebrospinal fluid. Acta Neurol Scand 1970;46:243-48. Reynolds EH Linnell JC. Vitamin B12 deficiency, deles sclesis. Lancet 1987:920. Remin . Multiple sclerosis and vitamin B12 metabolism-a new clue. J Neurol Neurosurg Psy-

9 Cole MG, Prchal JF. Low serum vitamin B12 in Alzheimertype dementia. Age and Ageing 1984;13:101-5.

10 Karnaze DS, Carmel R. Low cobalamin levels in primary degenerative dementia. Arch Intern Med 1987;147: 429-31.

11 Gross JS, Weintraub NT, Neufeld RR, Libow LS. Pernicious anemia in the demented patient without anemia or macrocytosis. J Am Geriatr Soc 1986;34:612-14.

12 Lazar GS, Carmel R. Cobalamin binding and uptake in vitro in the human central nervous system. J Lab Clin Med 1981;97:123-33.

13 Reynolds EH, Gallagher BB, Mattson RH. Relationship between serum and cerebrospinal fluid folate. Nature between serum and

14 Renvoize EB, Gastkell RK, Klar HM. Results of investigations in 150 demented patients consecutively admitted to tions in 150 demented patients consecutively admitced

15 Reynolds EH, Rothfeld P, Pincus JH. Neurological disease associated with folate deficiency. $\mathrm{Br}$ Med J 1973;2: associated 